\title{
A FILOSOFIA DO DIÁLOGO DE MARTIN BUBER COMO CRÍTICA À MODALIDADE HOMESCHOOLING: UMA CONTRIBUIÇÃO PARA O DEBATE EDUCACIONAL BRASILEIRO
}

\author{
Chrystiano Gomes Ferraz ${ }^{i}$
}

\begin{abstract}
Resumo: No ano de 2019 a modalidade Homeschooling ganhou destaque nos debates sobre a Educação escolar brasileira, com investidas na tentativa de legalização da prática, mas acabou sendo temporariamente descartada. No contexto da pandemia do novo coronavírus a Educação formal vem sendo reavaliada. $\mathrm{O}$ presente artigo pretendeu dar foco a um dos processos pedagógicos da modalidade Homeschooling, especialmente, o que se refere à proposta de ensino-aprendizagem sem - ou com pouca - interação aluno-aluno para tecer uma crítica a partir da filosofia do diálogo de Martin Buber. O Homeschooling pode oferecer uma educação integral às crianças e aos adolescentes em fase escolar? Entendeu-se que a limitação do convívio com outros alunos pode ser um fator negativo do Homeschooling, prejudicial à formação integral do aluno e do sentido comunitário de sua existência enquanto ser relacional. A relação com o outro é geradora de identidade e parte importante do processo de socialização de crianças e adolescentes.
\end{abstract}

Palavras-chave: Educação Escolar; Filosofia do Diálogo; Homeschooling; Martin Buber.

\section{MARTIN BUBER'S PHILOSOPHY OF DIALOGUE AS A CRITICISM TO THE HOMESCHOOLING MODALITY: A CONTRIBUTION TO THE BRAZILIAN EDUCATIONAL DEBATE}

\begin{abstract}
In 2019, Homeschooling was part of the debates on Brazilian school education, with attempts to legalize the practice, but was temporarily discarded. In the context of the new Corona virus pandemic, formal education has been rethought. The present article intended to focus on one of the pedagogical processes of the Homeschooling modality, especially, which refers to the teaching-learning proposal without - or with little - student-student interaction to make a criticism based on Martin Buber's philosophy of dialogue. Can Homeschooling offer integral education to school children and adolescents? It was understood that the limitation of contact with others students during learning can be a negative factor in Homeschooling, harmful to the integral education of the student and the community sense of his existence as a relational being. The relationship with the other generates identity, it is an important part of the socialization process of children and adolescents.
\end{abstract}

Keywords: Schooling; Philosophy of Dialogue; Homeschooling; Martin Buber.

\section{Introdução}

No atual cenário do Brasil conturbado pela crise de credibilidade da política, toda e qualquer proposta - ou falta de busca por soluções - apresentada pelos governantes em 
exercício passaram a ser observadas com mais atenção, tanto pelos veículos de informação quanto pelo cidadão comum.

No calor das discussões e opiniões polarizadas, surgem posições estabelecidas antecipadamente e pré-dispostas a rejeitar opiniões contrárias, pois apenas o critério da preferência político-partidária parece ser obedecido. Tais atitudes não contribuem para se alcançar um entendimento, há pouco espaço para diálogos autênticos.

Além disso, vivemos na era da desinformação, onde a falsa notícia - as famosas fake news - chegam a todo tempo, tornando o horizonte ainda mais turvo. Para trazer mais nitidez às questões sociais, tornou-se ainda mais urgente a utilização da avaliação mais criteriosa, apoiada em bases sólidas do conhecimento, para oferecer análises mais seguras da realidade que se apresenta diante de nós.

Para tornar mais complexo o cenário descrito até aqui, fomos acometidos por uma pandemia, que nos obrigou a repensar nossos modos de viver. Diante do panorama da atual crise sócio humana, evidenciada pela pandemia do novo coronavírus, toda a vida em sociedade passa por uma revisão e pela busca por novos caminhos. A Educação escolar também está sendo repensada, assim como seu futuro após a iminente vitória sobre a COVID-19. O que será da educação escolar após a COVID-19?

No debate em torno do futuro da educação, ressurge uma alternativa recentemente levantada - e rejeitada - em nosso país: o Homeschooling. A implementação do Homeschooling no Brasil ainda é um debate embrionário no campo da política nacional. Dada a brevidade da questão no solo brasileiro, pouco se produziu academicamente neste sentido.

Não pretendendo esgotar o tema ou oferecer um parecer definitivo, mas um ponto de reflexão, este trabalho buscou analisar a questão do Homeschooling em um dos seus aspectos - a socialização e o convívio com outros alunos da mesma idade para o desenvolvimento e construção do "eu" - à luz da Filosofia do Diálogo de Martin Buber. Pensando a educação de forma integral e a necessária interpelação do outro para a formação do indivíduo. Fica a pergunta sobre a limitação do Homeschooling enquanto modalidade de ensino, principalmente, sobre a aparente limitação do processo de socialização do aluno, do convívio com alunos de idade e realidade aproximadas.

Primeiramente faremos uma breve apresentação da modalidade, assim como uma exposição da proposta de implementação do Homeschooling no Brasil. Em seguida, distinguimos o ponto-chave do debate que pretendemos empreender e sua importância para a formação de crianças e adolescentes, a saber: o convívio como aspecto importante para a formação de alunos em fase escolar. Por fim, apresentamos na obra $E u$ e $T u$ de Martin Buber, Revista Interinstitucional Artes de Educar. Rio de Janeiro, V. 7, N. 1 - pág. 398-409 janeiroabril de 2021: "Pedagogias Vitais: Corpo, Desejo e Educação" DOI: 10.12957/riae.2021.51783 
o ponto que mais interessa à nossa pesquisa no tocante a formação integral do indivíduo. Nas considerações finais, fizemos uma crítica ao Homeschooling à luz da Filosofia do Diálogo, de Martin Buber.

\section{A proposta de implementação do homeschooling no brasil}

Afinal de contas, o que é o Homeschooling? Começaremos pela tradução do termo. O termo inglês Homeschooling, em uma tradução literal para o português, significa educação domiciliar, tecnicamente, é " a prática de Educação que não acontece na escola, mas em casa. Pelo modelo, as crianças e jovens são ensinados em domicílio com o apoio de um ou mais adultos que assumem a responsabilidade pela aprendizagem" (SEMIS, 2019).

A prática do ensino doméstico, ainda sem a conceituação sistematicamente elaborada, não é algo novo na história. Antes do estabelecimento do que conhecemos como prática comum de ensino escolar, delegado às escolas especializadas em educação formal, os pais ensinavam aos seus filhos os ofícios da família, passando o legado profissional e, assim, transmitiam os ensinamentos básicos necessários para o sustento e à pertença social do grupo ao qual faziam parte. Sendo assim, no início. o espaço educacional não era necessariamente o escolar. Ele era o local da vida e do trabalho: o templo, a casa, a oficina, o barco etc. (BRANDÃO, 1982, p.32).

A educação formal no Brasil teve início com a missão da Companhia de Jesus em nosso solo, em meados do século XVI, período que remonta o contexto de colonização deste país e de empreendimento missionário evangelístico realizado pela Igreja Católica (SILVA, 2018, p.65). Foi só após a expulsão dos jesuítas por Marquês de Pombal e a conquista da Independência do Brasil (1822), que se deu a necessidade de uma nova configuração da educação formal. Foi então, que, em 1824, uma nova constituição foi criada "para estruturação do novo império. Essa Carta Magna declarou a intenção da gratuidade da instrução primária para todos os cidadãos e determinou os colégios e universidades como locais para o ensino de ciências, letras e artes" (SILVA, 2018, p. 66).

Depois de longa trajetória e períodos de reforma, a educação formal no Brasil foi regulamentada por lei, para a garantia do direito à educação para todo cidadão. É o que está expresso no Artigo 205 da Constituição Federal de 1988: “a educação, direito de todos e dever do Estado e da família, será promovida e incentivada com a colaboração da sociedade, visando ao pleno desenvolvimento da pessoa, seu preparo para o exercício da cidadania e sua qualificação para o trabalho" (BRASIL, 1988). Assim como, o Artigo 208, que reza sobre a Revista Interinstitucional Artes de Educar. Rio de Janeiro, V. 7, N. 1 - pág. 398-409 janeiroabril de 2021: "Pedagogias Vitais: Corpo, Desejo e Educação" DOI: 10.12957/riae.2021.51783 
responsabilidade do Estado de oferecer a "educação básica obrigatória e gratuita dos 4 (quatro) aos 17 (dezessete) anos de idade" (BRASIL, 1988). Porém, um fator limitador à implementação de uma nova modalidade de ensino no país, sem a devida regulamentação, é a interpretação do Artigo 246 do Código Penal, que prevê como crime de abandono intelectual, se os pais ou responsáveis não matricularem os filhos em escola pública ou privada sem motivo plausível (Cf. CÓDIGO PENAL, 1940).

Hoje, especialmente no Brasil, a educação formal - oferecida por redes públicas e particulares de ensino - parece um conceito solidificado na mentalidade da sociedade. Junto à educação escolar pública ou particular, militar, religiosa ou confessional, ressurge a possibilidade - para alguns, a necessidade - de implementação de uma nova modalidade escolar: o Homeschooling (COOPER, 2005, p. 9).

No pano de fundo dessa tentativa de implementação da modalidade de educação domiciliar está a discussão em torno do desmonte da educação pública e gratuita, que vem sendo empreendido pelas últimas medidas do atual governo federal. A desidratação dos investimentos voltados para a educação pública são notórios, quando, por exemplo, o Conselho Nacional de Educação (CNE) decidiu anular uma decisão que regulamentava o Custo AlunoQualidade (CAQ) e o Custo Aluno-Qualidade Inicial (CAQi), uma das bases estratégicas para se atingir o investimento de $10 \%$ do PIB na educação até o ano de 2024, como projeta o Plano Nacional de Educação (PNE). De igual modo, o acionamento da EC95 /2016 colocou a educação em profunda crise de recursos. Tal empreendimento segue uma política de estado neoliberal, "marcado pela mercantilização da política social justamente pela liberdade que o mercado oferece ao vender educação, saúde, dentre outros serviços" (DUTRA, 2019. p. 166). As consequências dessas medidas podem ser desastrosas para a educação pública, ultrapassam os limites de nossa reflexão aqui proposta.

Após o não reconhecimento do Homeschooling pelo Supremo Tribunal Federal (STF) no ano de 2018, por entenderem na ocasião que não havia legislação prevista para a modalidade, o atual Presidente da República Jair Messias Bolsonaro, assinou um Projeto de Lei (PL) 3261/2015 proposto pelo Deputado Federal e seu filho Eduardo Bolsonaro. O PL 3261/2015 busca viabilizar legalmente o ensino domiciliar na educação básica, formada por três fases escolares: Educação Infantil, Ensino Fundamental e Ensino Médio para os menores de 18 anos.

Ainda que tenha sido rechaçada a princípio, a tentativa de implementação da modalidade pode voltar, principalmente no contexto pós-pandêmico.

Muitas dúvidas surgirão sobre a modalidade Homeschooling se legalmente houver nova investida em sua legalização: qual a formação necessária para que pais ou profissionais Revista Interinstitucional Artes de Educar. Rio de Janeiro, V. 7, N. 1 - pág. 398-409 janeiroabril de 2021: "Pedagogias Vitais: Corpo, Desejo e Educação" DOI: 10.12957/riae.2021.51783 


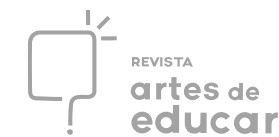

contratados ensinem às crianças e adolescentes em suas casas? Os conteúdos a serem estudados devem estar diretamente ligados com os conteúdos da Base Nacional Comum Curricular, utilizado nas escolas convencionais? Como aferir o nível de conhecimento apreendido pelos alunos de Homeschooling em comparação com os outros? Qual órgão fiscalizará a atividade de ensino domiciliar caso seja implementada?

Em alguns países a modalidade está autorizada, um deles é o Estados Unidos da América, em pelo menos 50 Estados (REICH, 2005, p. 109). Mesmo assim, há uma constante crítica ao Homeschooling no tocante à falta de regulamentação e fiscalização, assim como a razão pelas quais os responsáveis escolhem o modelo - não mais por terem crianças com necessidades especiais, questões emocionais, por serem atletas ou exercerem atividades profissionais que limitam o tempo - em grande parte, o perfil aponta para famílias religiosas fundamentalistas, majoritariamente protestantes, adeptos do liberalismo econômico. (WEST, 2009). Estes escolhem "proteger" seus filhos das ameaças da diversidade das correntes de pensamentos apresentados pela realidade social atual. Assim, tentam garantir um mundo unívoco e "seguro". Esta é uma realidade norte-americana (Cf. WEST, 2009).

Dentre os países que aprovaram a prática temos a Nova Zelândia, França, Noruega, Áustria, entre outros. Na Alemanha, por exemplo, como em outros países, a prática do ensino escolar doméstico ainda é crime.

Não nos importa, especialmente para este trabalho, o debate jurídico em torno da questão. Importa-nos saber se na prática do Homeschooling as crianças e adolescentes experimentam um satisfatório desenvolvimento social, importante para a sua formação como indivíduo, já que o convívio com outros alunos é bastante limitado nesse modelo. Pode o modelo estudado preencher satisfatoriamente a necessidade de convívio com as outras crianças da mesma idade? Em qual sentido seria um prejuízo aos alunos tal falta?

\section{O convívio como aspecto importante para a formação de alunos em fase escolar}

Não temos um conceito único e definitivo sobre o que é a Educação. Este é um conceito muito difícil de ser satisfatoriamente definido sem que se delimite precisamente o tipo de educação a qual nos referimos, dada a sua abrangência, o seu alcance e suas matizes. Assumiremos, pois, um conceito sobre educação, sem pretender problematizá-lo.

O dicionário Michaelis Online define a palavra educação da seguinte maneira: "processo que visa ao desenvolvimento físico, intelectual e moral do ser humano, através da Revista Interinstitucional Artes de Educar. Rio de Janeiro, V. 7, N. 1 - pág. 398-409 janeiroabril de 2021: "Pedagogias Vitais: Corpo, Desejo e Educação" DOI: 10.12957/riae.2021.51783 
aplicação de métodos próprios, com o intuito de assegurar-lhe a integração social e a formação da cidadania” (MICHAELIS, 2019, grifo nosso).

Um elemento nos parece um ponto pacífico em relação à educação: dentro do processo educacional está o necessário processo de integração social, vital ao ser humano. No mundo, que é uma grande casa comum a todo ser humano, vivemos com os outros, desde a comunidade tribal mais simples às grandes cidades, o ser humano está em relação com seus semelhantes.

Sabemos que a Educação não está circunscrita apenas ao espaço escolar. Brandão afirma que, mais importante do que o espaço físico é o processo educacional que envolva o exercício da convivência:

A educação do homem existe por toda parte e, muito mais do que a escola, é o resultado da ação de todo o meio sociocultural sobre os seus participantes. É o exercício de viver e conviver o que educa. E a escola de qualquer tipo é apenas um lugar e um momento provisórios onde isto pode acontecer. Portanto, é a comunidade quem responde pelo trabalho de fazer com que tudo o que pode ser vivido-e-aprendido da cultura seja ensinado com a vida - e também com a aula - ao educando. (BRANDÃO, 1982, p. 47)

O sentido comunitário da educação não pode ser negligenciado. Como pretendemos sublinhar, dentro do papel das instituições de educação formal não estão apenas a transmissão dos conteúdos acadêmicos pelos professores, os métodos utilizados pelos profissionais de ensino e suas didáticas específicas, mas outros elementos que igualmente colaboram para a formação dos alunos e da comunidade. Destacamos como ponto positivo da Educação Escolar, o convívio entre os alunos, da mesma - e de diferentes - faixas de idade e etapas diversas de desenvolvimento.

Vale lembrar que o "aprender a conviver" está em os quatro pilares da educação para o século XXI (Cf. UNESCO, 2010) A Educação Básica deve, portanto, incluir o convívio com a diversidade, priorizar tal objetivo. Se faz importante pensar que, durante a fase escolar: " $a$ criança relaciona-se com diferentes pessoas e com vários graus de conhecimentos, possibilitando vivenciar relações de igualdade, cooperação, competição, submissão, liderança, entre outras" (CAMPOS, 2013. p. 135). Para a criança em fase escolar, a convivência se torna muito importante para o seu desenvolvimento integral, necessidade que se assevera com o passar dos anos:

Vale ressaltar que, nesta fase, aparece na criança a necessidade de amizades mais duradouras e da convivência com companheiros. Essas necessidades se intensificam à medida que a ela se aproxima da adolescência. Geralmente, participa de grupos homogêneos quanto ao sexo, idade e classe social. Por 
exemplo: a criança dirá que outra é sua amiga pelo fato de ambas se ajudarem quando precisam e por elas terem gostos semelhantes. (CAMPOS, 2013. p. 135)

Portanto, se pensamos em educar de forma integral e integradora, não devemos negligenciar a importância do convívio entre os alunos em fase escolar, aspecto determinante para a formação do ser humano.

Porém, existem aspectos negativos que podem marcar a criança nessa etapa de desenvolvimento. A má convivência com os colegas de turma por exemplo, crianças que sofrem bullying, pode desenvolver traumas psicológico e danos à socialização, além de produzir comportamentos inadequados. Há, quase sempre, o "risco" do convívio. Em pesquisa que compara alunos de Homeschooling e alunos que vão à escola convencional, foi apontado um certo equilíbrio entre as incidências de questões de comportamento inadequado e problemas emocionais entre os alunos das duas modalidades de ensino, variando entre faixas etárias (Cf. GUTERMAN; NEUMAN, 2017).

Podemos encontrar também, pesquisas que garantem o sucesso do Homeschooling no tocante a socialização dos alunos submetidos à prática (Cf. RAY, 2005). Porém, há grande dificuldade em aferir tais resultados. A realidade, de um modo geral, é que dificilmente - salvo casos específicos - o Homeschooling consegue oferecer o convívio entre alunos da mesma faixa etária durante o processo de ensino. O processo de ensino-aprendizagem, consequentemente, é mais individualizado - o que tem seus pontos positivos -, limitando-se comumente à relação professor-aluno.

Veremos agora, o que a Filosofia do Diálogo, de Martin Buber pode acrescentar ao debate em torno da questão do processo de formação identitária do ser humano.

\section{A Filosofia do Diálogo, de Martin Buber}

Agora, em linhas gerais, apresentaremos a contribuição da Filosofia do Diálogo, de Martin Buber, e a sua visão da experiência humana através da relação com o outro, como aquela que possibilita a existência humana. Daremos um maior foco na obra $E u$ e $T u$, principal obra de Buber, especialmente, pelo potencial hermenêutico que a obra oferece à compreensão do pensamento do autor.

Martin Mordechai Buber foi um filósofo e pedagogo, nascido em 1878 na Áustria e naturalizado israelita. Veio a falecer em 1965. Suas principais contribuições estão voltadas para Revista Interinstitucional Artes de Educar. Rio de Janeiro, V. 7, N. 1 - pág. 398-409 janeiroabril de 2021: "Pedagogias Vitais: Corpo, Desejo e Educação" DOI: 10.12957/riae.2021.51783 
a ideia de que não há existência humana de fato sem diálogo e comunicação, que se dá, essencialmente, na relação "Eu e Tu" (ZANK, 2014). Nas suas obras estão impressas uma experiência existencial, mais do que um tratado sistemático, a filosofia de Buber é arraigada na vivência, na práxis.

Logo no início da obra por nós enfatizada - “Eu e Tu” - Buber afirma ser duplo o mundo do homem, pois a sua atitude diante desse mundo é dual: de relação Eu-Tu e Eu-Isso (BUBER, 1974, p. 3). A relação "Eu-Isso" refere-se à experiência do homem com as coisas, os objetos que se dispõe a estar diante, a conhecer por esforço intelectual. Outra pessoa pode até ser um "Isso" em algum instante, mas só quando o "Eu" a observa, a contempla sem que haja um encontro efetivo de reciprocidade. Nota-se a passividade do "Isso" contemplado, observado. Está aí uma das distinções entre a relação "Eu-Isso" e "Eu-Tu”, pois falta ao "Eu-Isso" a relação recíproca de interpenetração do "Eu" no "Isso".

A relação "Eu-Tu" é a relação com este outro "mundo" que não sou "Eu", mas uma pessoa como eu, um "Tu". O encontro entre "Eu-Tu" se dá pela "palavra". Entende-se "palavra" não apenas como uma "fala", comunicação verbalizada, mas no seu múltiplo potencial comunicativo. É a comunicação, o diálogo que nos proporciona o encontro com o outro, não numa relação "Eu-objeto", mas na reciprocidade do reconhecimento da alteridade. “Eu-Tu” é um encontro que se dá subjetivamente, na igualdade, que na relação de alteridade nos conduz à intersubjetividade.

Buber situa o homem em três relações originárias: com Deus, com o outro e com a natureza. Fazendo uma releitura do que as Escrituras Sagradas judaico-cristãs apresentam como o princípio, Buber sugere uma importante interpretação dessa narrativa: "No começo é a relação" (BUBER, 1974, p. 20). Como judeu, Buber pensa a "Palavra" como atividade criadora, geradora de tudo. Segundo essa tradição religiosa, através da "palavra" - proferida por Deus - o mundo foi criado, assim como o homem - e a mulher. O que Buber quer aclarar é que a existência só é possível pela "palavra criadora", pelo diálogo e comunicação. Somos, portanto, seres relacionais porque temos impresso em nós a vocação da comunicação, do encontro interpelador com o "Tu", que se dá pelo diálogo. Nessa relação o " $E u$ " percebe a consciência de si, enquanto contempla a condição singular do outro - “Tu” - como pessoa.

Uma palavra-chave no pensamento de Buber, é a palavra diálogo. Assim confirma Zuben na introdução da obra estudada: “De fato, 'diálogo' é uma categoria que pode servir de via de acesso a compreensão da obra de Buber. 'Diálogo' foi o tipo de compromisso de relação que a vida e a obra deste autor selaram entre si”. (ZUBEN, N. A. In: BUBER, M.,1974, p. $\mathrm{XX)}$. 
Pensando na etimologia da palavra de origem grega, pode-se observar que sua composição se dá pela junção de dois termos: "dia" e "logos". O teólogo Faustino Teixeira faz uma interpretação desses dois termos que podem nos abrir um caminho para interpretá-la em Buber com mais precisão:

A expressão "logos" cobre uma vasta gama de significados, mas indica em particular o dinamismo racional do ser humano, a capacidade humana de pensamento e raciocínio. O termo "dia", por sua vez, expressa uma dupla ideia: alude ao que separa e divide, mas igualmente à ultrapassagem de um limite. Faz parte da natureza do diálogo a busca de unidade que preserve e salvaguarde a diferença e a liberdade. (DIAS \& TEIXEIRA, 2008 p. 124)

O diálogo pressupõe, portanto, o encontro com a alteridade, com o diferente que ao mesmo tempo interpela e é interpelado. Se faz importante pontuar, que Buber entende o ser humano como dialógico não apenas pelo relacionamento entre si, mas, também, "é o seu comportamento, a sua atitude um-para-com-o-outro, cujo elemento mais importante é a reciprocidade da ação interior" (BUBER, 1982, p. 8). A autenticidade do diálogo se dá pela abertura ao outro, pelo reconhecimento da alteridade entre os interlocutores, pelo respeito mútuo, que contempla a liberdade do ser enquanto diferente.

Podemos passar agora para o ponto que nos parece culminante: “ $O$ Eu se realiza na relação com o Tu; e tornando Eu que digo Tu. Toda vida atual é encontro" (BUBER, 1974, p. 13). Afirma-se então a tese central de que só existimos na relação. O encontro inter-humano possibilita a existência humana de fato. Esse encontro é uma disposição ontológica do nosso ser: “O tu encontra-se comigo por graça; não é através de uma procura que é encontrado. Mas endereçar-lhe a palavra-princípio é um ato de meu ser, meu ato essencial" (BUBER, 1974, p. 12).

Outro aspecto extremamente relevante para o processo pedagógico e uma das ênfases na educação buberiana é o sentido, o processo e o objetivo comunitário da educação: “ $A$ educação para a comunidade não pode ser teórica ou, em termos mais claros, a educação para a comunidade só pode ocorrer através da comunidade" (BUBER, 2008, p. 90).

Como constata a educadora Gizele Parreira, para Buber

só é possível educar por meio da interação verdadeira e recíproca, por meio do coexistir espontâneo, porque o que seguramente educa a pessoa, seja a criança ou o adulto, é a relação autêntica, a existência pessoal, a presença e a responsabilidade de quem se dedica à função educadora. (PARREIRA, 2016. p. 195) 


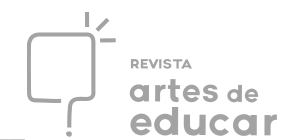

A pessoa não se forma só, não se instruí por si e para si, ela está inserida em um contexto mais amplo, comunitário. A comunidade autêntica se constrói por meio de relações humanas, pelo encontro gerador de laços que nos livram do individualismo egoísta e da angústia da solidão.

A educação para a comunidade envolve a pertença, assim como, a responsabilidade da pessoa, do indivíduo para com os outros. Não se pode almejar uma sociedade melhor sem que os indivíduos que a compõe tenham plena consciência de sua responsabilidade com o todo.

Concluímos esta breve explanação com a afirmação de que o encontro inter-humano é sempre um risco, mas sem correr o risco do encontro " $E u$ - $T u$ " não há manifestação completa da nossa humanidade: diálogo é plenitude, “deve-se correr o risco, é necessário atirar-se na água e nadar" (ZUBEN, 2001).

\section{Considerações finais}

Colocando em contato a Filosofia do Diálogo, de Martin Buber - a vitalidade da relação inter-humana e sua necessidade para a existência enquanto humanos - com a necessidade do convívio entre os alunos em fase escolar para o desenvolvimento integral do indivíduo, firmaremos nosso ponto de reflexão a ser considerados sobre a prática do Homeschooling. A filosofia de Buber pode ser aplicada às mais diversas áreas da vida, inclusive à pedagogia. Em outras obras, o autor dedicou explicitamente sua reflexão ao ensino, como por exemplo $D a$ Função Educadora (1982), texto traduzido para o português e publicado na Revista Reflexão.

Primeiramente, não é nossa intenção legitimar ou não a prática, mas oferecer mais um elemento a ser considerado na avaliação do Homeschooling enquanto modalidade de ensino. Entendemos como vital ao processo de ensino-aprendizagem a promoção do convívio entre os alunos em fase escolar, já que, na relação entre os alunos, pode ocorrer o encontro genuíno entre " $E u$ e $T u$ ". Pode a relação entre " $E u$ e $T u$ " acontecer no encontro professor-aluno? Sim, e deve acontecer. Esse encontro genuíno também é parte importante do processo pedagógico, porém, não pode substituir plenamente o encontro promovido pela relação aluno-aluno.

Como se pode garantir que a modalidade Homeschooling irá promover a prática do convívio com crianças e adolescentes da mesma idade no processo de desenvolvimento dos alunos? Esta é a pergunta que precisa ser satisfatoriamente respondida, para que a modalidade seja mais efetiva e justificável. Não oferecemos aqui alternativas para tal, mas está colocada a importância da questão. Que autoridades competentes, políticos, órgãos de fiscalização, 
educadores, pais, responsáveis legais, enfim, que todos os envolvidos no processo de legalização ou não do Homeschooling possam levar em consideração o poder e a necessidade do elemento aqui colocado, para que não haja prejuízo à formação humana das nossas crianças e adolescentes e, consequentemente, à sociedade. Que este debate, que é multidisciplinar, seja alimentado pelos campos do saber por ele tangenciados, para facilitar nas tomadas de decisão dos rumos da educação pós-pandemia.

\section{REFERENCIAS}

BRANDÃO, Carlos Rodrigues. O que é Educação? São Paulo: Brasiliense, 1982. 116 p.

BUBER, Martin. Do diálogo e do dialógico. [tradução Marta Ekstein de Souza Queiroz e ReginaWeinberg]. São Paulo: Perspectiva, 2007.

Eu e Tu. [tradução Newton Aquiles von Zuben]. São Paulo: Editora Moraes, 1974.

Sobre comunidade. São Paulo: Perspectiva, 2008.

CAMPOS, Juliane Aparecida de Paula Perez; [et.al.]. Psicologia da Educação. Batatais-SP: Claretiano, 2016.

BRASIL. CASA CIVIL. Código Penal, 1940. Disponível em: < http://www.planalto.gov.br /ccivil_03/decreto-lei/del2848compilado.htm>. Acesso em 19 de março de 2019.

BRASIL. CONSTITUIÇÃO DA REPÚBLICA FEDERATIVA DO BRASIL DE 1988. Disponível em:<http://www.planalto.gov.br/ccivil_03/constituicao/constituicao.htm> Acesso em:10 de março de 2019.

COOPER, Bruce S. (Org.). Homeschooling in Full View: A Reader. Greenwich, CT: Information Age Publishing, 2005.

DIAS, Z. M.; TEIXEIRA, F. Ecumenismo e Diálogo Inter-religioso: a arte do possível. Aparecida, SP: Editora Santuário, 2008.

DUTRA, Maria de Fatima da Conceição; FREITAS, Renan Moura de. Os Impactos da Emenda Constitucional 95 na Educação Pública. Revista Semana Pedagógica, v.1, n.1, 2019. p. 165-167.

GUTERMAN, Oz; NEUMAN, Ari. Schools and emotional and behavioral problems: A comparison of school-going and homeschooled children. Journal of Educational Research. 2017, Vol. 110 Issue 4, p. 425-432.

MICHAELIS, Dicionário Brasileiro da Língua Portuguesa. Rio de Janeiro: Editora Melhoramentos, 2019. 


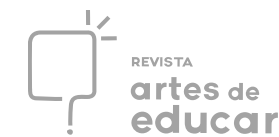

NEUMAN, Ari; GUTERMAN, Oz. Structured and unstructured homeschooling: a proposal for broadening the taxonomy. Cambridge Journal of Education. Sep.2017, Vol. 47 Issue 3, p. 355-371.

PARREIRA, Gizele Geralda. Martin Buber e o sentido da educação. Goiânia: IFG, 2016.

RAY, Brian D. A homeschool Research Story. In: COOPER, Bruce S. (Org.). Homeschooling in Full View: A Reader. Greenwich, CT: Information Age Publishing, 2005.

REICH, Rob. Why Home Schooling should be regulated. In: COOPER, Bruce S. (Org.). Homeschooling in Full View: A Reader. Greenwich, CT: Information Age Publishing, 2005, p.109-120.

SEMIS, Laís. Homeschooling: 14 perguntas e respostas. Disponível em: <https://novaescola. org.br/conteudo/15636/homeschooling-14-perguntas-e-respostas>. Acesso em: 19 de março de 2019.

SILVA, Bruno de Oliveira; et.al. A busca pela história da Educação Formal. Revista de Educação, Paripiranga, Bahia, Brasil, v. 1, n. 2, p.63-72, jan./jun. 2018.

UNESCO. International Commission on Education for the Twenty-first Century. Educação: um tesouro a descobrir, relatório para a UNESCO da Comissão Internacional sobre Educação para o Século XXI (destaques). Brasília: UNESCO, 2010. Disponível em: <https://unesdoc.unesco.org/ark:/48223/pf0000109590_por> Acesso em: 10 de março de 2019.

WEST, Robin L. The Harms of Homeschooling. Philosophy \& Public Policy Quarterly, vol. 29, NO. 3/4, Summer/Fall, 2009.

ZANK, Michael. Stanford Encyclopedia of Philosophy. 2014. Disponível em: <https://plato.stanford.edu/entries/buber/>. Acesso em: 02 de maio de 2019.

ZUBEN, Nilton Aquiles Von. Introdução. In: BUBER, Martin. EU e TU. Tradução do alemão, introdução e notas por Newton Aquiles Von Zuben. São Paulo: Centauro, 2001. p. 7-49.

\footnotetext{
${ }^{\text {i }}$ Chrystiano Gomes Ferraz é mestre e doutorando em Teologia pela Pontifícia Universidade Católica do Rio de Janeiro (PUC-Rio), bacharel em Teologia pelo Seminário Teológico Batista do Sul do Brasil (STBSB), licenciado em Filosofia pelo Centro Educacional Claretiano e especialista em Filosofia pela Universidade Cândido Mendes (UCAM). E-mail: chrysferraz@hotmail.com. ORCID iD https://orcid.org/0000-0002-0140-5996.
} 